\title{
Discussion on the Disclosure of Accounting Information of Listed Companies
}

\section{Wensheng Zhang}

Shenzhen Comix Group Co., Ltd., Shenzhen, Guangdong, 518000, China

\begin{abstract}
The development of listed companies needs financial support, and the securities market is one of the main financing channels. The securities market requires listed companies to disclose accounting information that can meet the needs of the effective market, but the accounting information disclosed at present can not meet the needs of the market. The defects of such disclosure restrict the securities market to play the function of resource allocation.
\end{abstract}

\section{Keywords}

accounting information; disclosure; listed companies

\section{上市公司会计信息披露探讨}

张文胜

深圳齐心集团股份有限公司，中国・广东深圳 518000

\section{摘 要}

上市公司自身发展需要资金支持, 证券市场是主要的融资渠道之一。证券市场要求上市公司披露能满足有效市场所需要的会 计信息，而目前披露的会计信息还不能满足市场的需要，这种披露的缺陷制约证券市场发挥资源配置的功能。

\section{关键词}

会计信息；披露；上市公司

\section{1 引言}

会计信息是上市公司需要披露的一类信息。在对各种信 息非常敏感的资本市场上，会计信息显示了独特的价值，是 实现 “三公” 原则的基础保证之一。

\section{2 会计信息披露}

会计信息是指反映企业价值运动的可以计量的一种经济 信息 ${ }^{[1]}$ 。一般包括财务会计报表、财务状况说明书、报表附注、 企业临时公告、审计报告等。这些信息具有可理解、可比较、 可靠和相关等特点。

会计信息披露, 是指上市公司按照交易和监管机构的要 求用规定形式, 向相关利益各方和监管机构公开与证券发行

【作者简介】张文胜 (1969-), 男, 研究生学历, 会计师, 任 职深圳齐心集团股份有限公司财务主管, 从事企业财务管理 研究。
和交易有关的会计信息的行为。包括招股说明书，上市后在 规定的时间公开披露的财务季报、半年报和年度报告，各类 上市公告书等。

上市公司披露的会计信息能够影响投资者的决策，因此 上市公司应该严格按照有关法律和法规规范披露企业会计信 息, 确保企业的经营状况在信息中能真实反映。

\section{1 会计信息披露的基础理论}

\section{1 .1 有效性理论与会计信息披露}

芝加哥大学会计学院教授尤金法码于 1970 年研究发现, 如果所有的信息以不带任何偏见的方式能够在证券价格中及 时得到反映 ${ }^{[2]}$, 那么可以认为该市场是有效的。这就是会计 学中著名的“有效市场假说理论”。

\section{以公开披露的会计信息对市场上证券价格影响的程度划} 分, 可分为强有效、半强有效、弱有效等。现实市场多数情 况下显示半强有效, 此时上市公司只要公布会计信息其股价 
就会调整，从而导致市场资源配置的变化。

\section{1 .2 不对称信息与会计信息的披露}

信息不对称，是指证券市场上的某些参与人通过一定的 方法掌握了某类信息, 而其他参与人没有掌握该类信息, 这 样在市场交易中参与人处于不平等状态。无论买家还是卖家, 当任何一方获得更多交易标的信息时，都会选择对自己有利 的交易行为。而发生这些特定选择或有失道德标准的行为导 致市场对信息失效。

\section{3 上市公司披露会计信息的现状}

中国一直在建立并完善上市公司会计信息披露体系，经 过多年努力在上市公司会计信息披露上建立了多层次的法律 和法规, 如图 1 所示。

这套规范分为以下层次: 证券行业自律法规、部门规章 制度、行政法规和国家法律。《中华人民共和国会计法》和《中 华人民共和国证券法》等是这套规范的核心，其他法规和规 章制度等是重要的补充。这套体系加大了对证券市场的管理 力度。然而现行制度还不完善, 少数上市公司披露会计信息 依然存在不客观的现象。

\section{4 上市公司会计信息披露存在的主要问题}

\section{1 信息客观性较差}

信息客观性较差是上市公司在会计信息披露中较严重的 问题。少数上市公司弄虚作假，夸大或隐瞒财务报表信息， 有意披露虚假的会计信息。其表现有以下三个方面。

\subsection{1 操纵预测公司盈利}

经过广泛征集市场各方的意见，1998 年中国证监会要求 所有上市公司必须进行业绩预告, 其目的是给公司大小股东、 投资者和各方债权人，提前了解在过去的经营期间里公司运 营和财务成果，在保证知情权的前提下，提前消除业绩不确 定性，降低市场上因信息不对称产生的危害。

然而，少数上市公司在利益的驱动下通过业绩预告误导 投资者的投资行为。如某上市公司在一季度刊披露上年度业 绩预告时，在预告中称公司上年度净利润约有 7099 万元。而 后在该公司 4 月再次发布业绩公告,净利润被修正为 302 万元， 直到正式年报披露结果跟修正公告一致。巨大的反差令市场 投资者极为愤怒，交易所对该公司主管财务负责人进行了通 报批评。

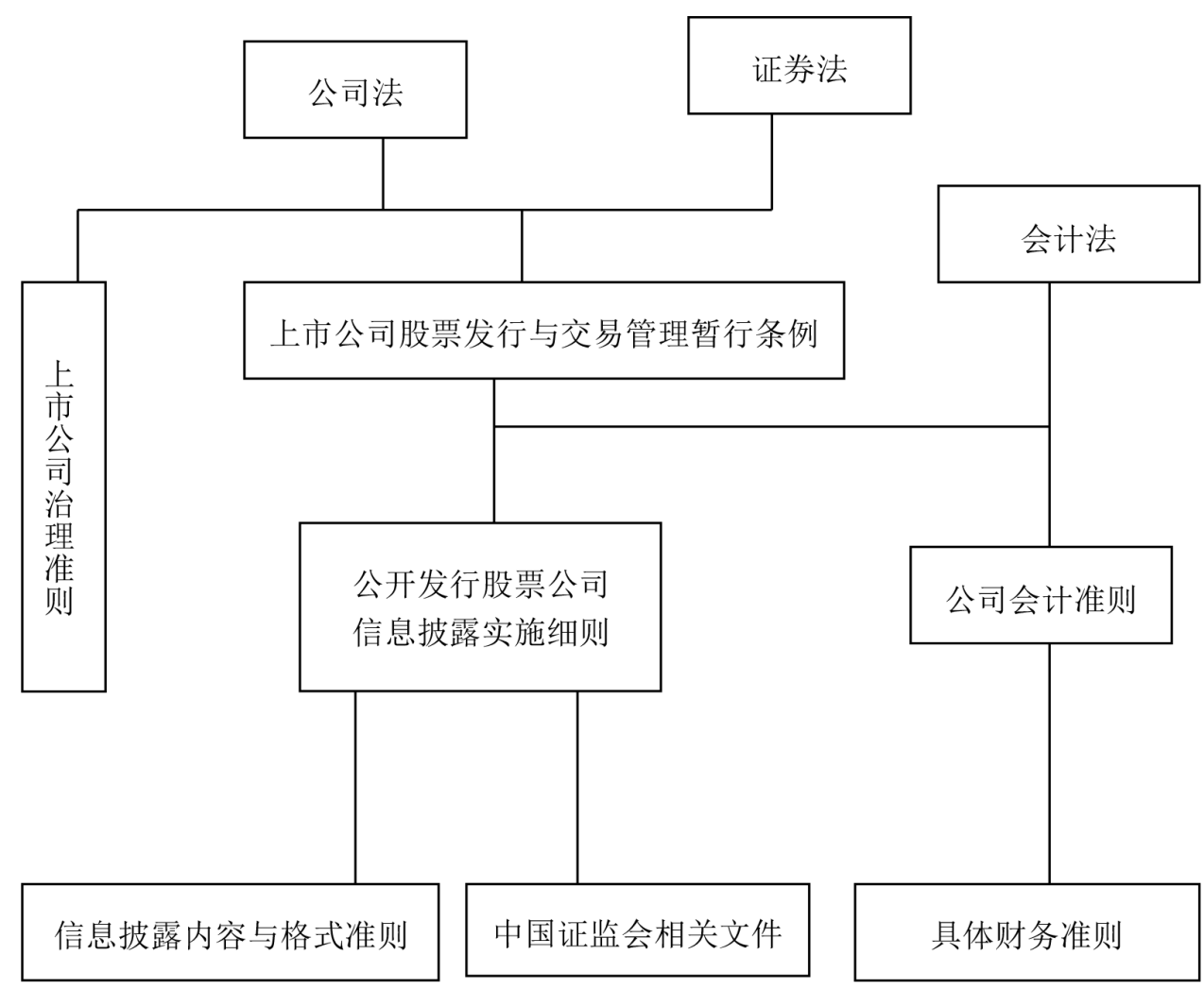

图 1 中国会计信息披露法律法规体系 


\subsection{2 利润严重失实}

利润不实是指上市公司为了达到不可告人的目的，有选 择性地故意谎报公司真实经营结果。谎报经营结果对市场投 资者危害较大，早期蓝田股份和近年的圣莱达等案件属于这 类情况。

\subsection{3 审计报告弄虚作假}

会计事务所属于社会中介机构, 要自负盈亏。调查发现, 在会计事务所对上市公司审计时, 少数审计人员未恪尽职守, 未体现应有的公正和独立，不但没查出上市公司报表中的虚 假信息，甚至和上市公司合谋弄虚作假。

\section{2 信息披露及时性不够}

披露的会计信息能影响股价，从而实现资本市场对公司 管理层的制约。上市公司大股东和高管存在影响披露会计信 息时间、重大事项未及时对外发布公告等现象。

\section{3 信息披露不充分}

会计信息披露不充分是指上市公司没有完整翔实地披露 会计信息。主要表现为对投资项目、现在和未来偿债能力、 关联公司的交易行为、市场和经济政策变化等方面对公司影 响的披露不充分。

\section{5 促进上市公司会计信息披露的探讨}

\section{1 完善信息披露的道德法律体系}

上市公司的管理层和中介机构一般是会计信息披露违规 主体。目前对违规主体主要实施以行政处罚为主其他处罚为 辅的责任体系，这种体系没有达到有效的惩罚作用。

建立会计信息披露制度是为了保护广大投资者, 如果没 有建立相关民事赔偿责任制度，信息披露制度制定得再好， 投资者的利益也无法得到合法的保护。可以参照国际成熟证 券市场的做法, 让使用虚假信息而受损的投资者对违法者提 起诉讼, 要求赔偿损失, 让违法者付出应有的代价并将其逐 出证券市场。

从保护广大投资者利益角度考虑, 建立上市公司会计信 息披露法律责任的惩罚机制 ${ }^{[3]}$ 势在必行。这种多层次监管体 制以民事诉公为核心，刑事诉公和行政处罚为辅助。

\section{2 完善政府对信息披露的监管体系}

监管部门对上市公司会计信息披露监管深度和效率目前 还不够, 应从以下几个方面改善:

\subsection{1 提高监管能力与效率}

建立符合中国国情的证券法律体系，组建一支高效、廉 明和公正的监管队伍, 精准打击上市公司披露虚假会计信息。 对监管人员加强职业道德教育, 严厉惩治队伍中的违法者, 发挥监管者的监督职能。

\section{2 .2 统一监管}

监管机构应对上市公司会计信息监督管理标准和权责进 行统一, 改革现行上市公司会计信息披露制度, 改革证券市 场监管体制。证券监管部门和交易所各司其职, 一个负责制 定统一会计信息披露制度和证券市场政策；另一个则依法对 上市公司执行会计信息披露制度的日常行为进行监管。

\section{2 .3 建立上市公司信息监管员制度}

由中国证监会及其驻各地分支机构派出监管员到各上市 公司，对各上市公司实行承包责任制，监管员对自己所负责 的上市公司披露的各种信息加以监督。

\section{3 完善上市公司会计信息披露制度}

确保 “三公”信息披露的制度，是提高上市公司披露会 计信息质量的重要保证, 可以最大限度保护市场参与者。监 管者完善会计信息披露方向有以下三方面。

\section{3 .1 建立一个良好的信息渠道}

上市公司的经营者与市场投资者之间发生信息不对称， 可以通过专门的信息披露网站来解决。监管机构管建立和管 理信息披露网站，对网络信息披露制定标准，提高披露信息 的速度，降低信息不对称给市场投资者造成的影响。

\section{3 .2 完善信息披露内容和缩短披露时间}

披露的会计信息内容应增加一系列表外信息、公司内部 控制分析报告等。

现在对外公布报表截止日有滞后性，因此严重影响信息 的有效性，如年报还未披露季报已出来了，年报和季报一起 披露等。年报信息披露的时间可适当提前并严格要求，保证 年报披露在前一季报披露在后，有利于市场和投资者对披露 信息理解的及时性和连贯性。

\section{3 .3 推动上市公司自愿披露信息}

公司法、证券法和交易所要求上市公司披露的会计信息, 这是一种强制性而非自愿的方式。上市公司主动提供更多更 透明的信息，便于投资者全面了解上市公司。因此，中国证 监会和交易所应推动建立自愿披露会计信息规范, 引导上市 
公司主动披露信息。

\section{4 完善会计人员职业道德教育体系}

会计的专业能力和道德水平是保证会计信息公正完整的 重要环节。因此, 对他们要进行专业能力和职业道德的定 期教育。

\section{5 完善社会审计准则}

目前会计事务所对上市公司进行审计时要收取高额审计 费。无形中增加了上市公司选择造假的概率，因此制定合理 的审计费用标准具有重要作用。

修改会计事务所服务上市公司的年限标准，降低合谋概 率。可以把会计事务所对同一家企业连续审计的时间改为不 超过三年。

\section{6 结语}

本文通过分析上市公司信息披露现状及存在的不足，提 出改变现状和保护广大投资者利益的有效措施。保护投资者 的利益需要通过政府的努力, 加快完善中国会计信息披露的 制度和道德法律体系，引进新审计准则 “社会审计”等各种 措施, 健全中国会计信息披露制度, 提高会计信息披露质量, 为资本市场健康发展保驾护航。

\section{参考文献}

[1] 傅赛萍. 政策选择与会计信息的质量探究 [J]. 江西电力职业技术 学院学报,2018,31(07):151-152.

[2] 陈继初. 会计信息透明度研究述评 [J]. 财会月刊 ,2008(34):50-52.

[3] 吴弘, 张金金. 证券民事赔偿的司法难题及其解决思路 [J]. 证券市场 导报,2001(12):60-63. 